American J. of Engineering and Applied Sciences 3 (2): 355-362, 2010

ISSN 1941-7020

(C) 2010 Science Publications

\title{
Finite Element Modeling of Transient Temperatures in a Small-Caliber Projectile
}

\author{
M. Brian Thomas and Leon Dozier \\ Department of Mechanical Engineering, Cleveland State University, \\ 1960 East 24th Street, Cleveland, Ohio 44115
}

\begin{abstract}
Problem statement: Future generations of intelligent munitions will use Microelectromechanical Systems (MEMS) for guidance, fuzing logic and assessment of the battlefield environment. The temperatures fund in a gun system, however, are sufficient to damage some materials used in the fabrication of MEMS. The motivation of this study is to model the dynamic temperature distribution in a typical small-caliber projectile. Approach: An axisymmetric finiteelement model of a projectile is developed to simulate temperatures through internal ballistics (the projectile is in the gun barrel) and external ballistics (the projectile travels in a free trajectory towards the target). Accuracy of the simulation is confirmed through comparison to analytical models and to payloads attached to experimental projectiles. In the simulation, the exact values for some boundary conditions are unknown and/or unknowable. A sensitivity analysis determines the effect of these uncertain parameters. Results: The simulation shows that friction at the projectile-gun barrel interface is primarily responsible for elevated temperatures in a gun system. Other factors have much smaller effects. The short duration of the internal ballistics prevents the frictional heat from diffusing into the bulk of the projectile. As a result, the projectile has a shallow, high-temperature zone at its bearing surface as it leaves the gun barrel. During external ballistics, this heat will diffuse through the projectile, but most of the projectile experiences temperatures of $56^{\circ} \mathrm{C}$ or lower. Simulation shows that the polymer package around a MEMS device will further attenuate heat flow, limiting temperatures in the device to less than $30^{\circ} \mathrm{C}$. Conclusion: The finite element model demonstrates that a MEMS device may be engineered to survive temperatures expected in the ballistic environment.
\end{abstract}

Key words: Ballistics, finite element modeling

\section{INTRODUCTION}

Intelligent weapon systems are deployed for the purposes of guiding munitions, optimizing fuzing logic and providing real-time assessment of the battlefield environment (Tuscon, 2006; 2008; Tobik, 2006; Schubert and Kraus, 1995). Over time, these technologies have been miniaturized and deployed in ever-smaller weapon systems, with the leading edge found in munitions for man-portable grenade launchers (Goodin and Alexander, 2002; Kleiner, 2009). Extrapolating this trend, it is feasible that Microelectromechanical Systems (MEMS) will soon bring intelligent capabilities to small-caliber munitions, considered here as 0.50 caliber $(12.7 \mathrm{~mm})$ and smaller.

One challenge to the future deployment of MEMS is the presence of harsh temperatures, capable of damaging MEMS materials, in the ballistic environment. Using a high-speed infrared camera,
Richards measured the temperature of a bullet leaving a military rifle at $267^{\circ} \mathrm{C}$ (Richards, 2002). Even in the normal handling of munitions, elevated temperatures can be encountered. In evaluating ordinance, the US Army will cycle temperatures from $-60^{\circ} \mathrm{F}$ to $+160^{\circ} \mathrm{F}$ ($51^{\circ} \mathrm{C}$ to $\left.+71^{\circ} \mathrm{C}\right)$, thirty times, before acceptance (Carlucci et al., 2006).

The motivation of this study is to evaluate the thermal environment for MEMS in a small-caliber projectile through the ballistic cycle. To the knowledge of the authors, this topic has not been previously addressed. Previous numerical analyses of gun systems have modeled the linear motion of the projectile (Stiefel, 1988), flexure of a gun barrel through the ballistic cycle (Ahmed et al., 2008) and the interaction of a solid propellant with combustion gasses during internal ballistics (Ray and Tezduyar, 2000). This study develops an axisymmetric finite-element simulation, written in MATLAB (The MathWorks, Inc.), to model

Corresponding Author: M. Brian Thomas, Department of Mechanical Engineering, Cleveland State University, 1960 East 24th Street, Cleveland, Ohio 44115 Tel: 1-216-523-7251 Fax: 1-216-687-5375 
dynamic temperatures through the internal and external phases of the ballistic cycle. The accuracy of the simulation results is confirmed through comparison to analytical models and further supported by observations of experimental articles. The sensitivity of the predicted temperatures to uncertain and unknown parameters in the simulation is also assessed.

\section{MATERIALS AND METHODS}

Finite element model: Finite-element model. This study models the dynamic temperatures in a smallcaliber projectile fired from a rifled barrel. The projectile is modeled as an axisymmetric body, with its geometry defined in the axial-radial ( $\mathrm{r}-\mathrm{z}$ ) half-plane. In a real projectile, circumferential variations in temperature are expected between the rifling grooves; these variations in temperature are ignored in this study.

In cylindrical coordinates, the thermal diffusion equation is expressed as:

$$
\frac{1}{\mathrm{r}} \frac{\partial}{\partial \mathrm{r}}\left(\mathrm{kr} \frac{\partial \mathrm{T}}{\partial \mathrm{r}}\right)+\frac{1}{\mathrm{r}^{2}} \frac{\partial^{2} \mathrm{~T}}{\partial \varphi^{2}}+\frac{\partial}{\partial \mathrm{z}}\left(\mathrm{k} \frac{\partial \mathrm{T}}{\partial \mathrm{z}}\right)+\dot{\mathrm{q}}=\rho \mathrm{c} \frac{\partial \mathrm{T}}{\partial \mathrm{t}}
$$

Where:

$$
\begin{aligned}
\mathrm{r}, \mathrm{z} \text { and } \phi= & \text { The radial, axial and circumferential } \\
& \text { coordinates } \\
& \text { The material's thermal conductivity } \\
\mathrm{k} \quad & \left(\mathrm{W} \cdot \mathrm{m}^{-2} \cdot \mathrm{K}^{-1}\right) \\
= & \text { The internal rate of heat generation per } \\
\dot{\mathrm{q}} & \text { unit volume }\left(\mathrm{W} \cdot \mathrm{m}^{-3}\right) \\
= & \text { The density }\left(\mathrm{kg} \cdot \mathrm{m}^{-3}\right) \\
\rho & =
\end{aligned}
$$

Assuming uniform temperatures in the circumferential direction, or $\mathrm{dT} / \phi=0$, Eq. 1 simplifies to:

$$
\frac{1}{\mathrm{r}} \frac{\partial}{\partial \mathrm{r}}\left(\mathrm{kr} \frac{\partial \mathrm{T}}{\partial \mathrm{r}}\right)+\frac{\partial}{\partial \mathrm{z}}\left(\mathrm{k} \frac{\partial \mathrm{T}}{\partial \mathrm{z}}\right)+\dot{\mathrm{q}}=\rho \mathrm{c} \frac{\partial \mathrm{T}}{\partial \mathrm{t}}
$$

For the finite-element simulation, the desired form of Eq. 2 in matrix notation is:

$$
\mathrm{M}_{\mathrm{GLOBAL}} \dot{\mathrm{T}}+\mathrm{K}_{\mathrm{GLOBAL}} \mathrm{T}=\mathrm{Q}
$$

Where:

$$
\begin{aligned}
\mathrm{M}_{\mathrm{GLOBAL}}= & \text { The global thermal capacity matrix } \\
& \left(\mathrm{W} \cdot \mathrm{s} \cdot \mathrm{K}^{-1}\right) \\
\mathrm{K}_{\mathrm{GLOBAL}}= & \text { The global conduction matrix }\left(\mathrm{W} \cdot \mathrm{K}^{-1}\right) \\
\mathrm{T}= & \text { The nodal temperature vector }(\mathrm{K}) \\
\mathrm{Q} & \text { The heat flow across boundary conditions } \\
& (\mathrm{W})
\end{aligned}
$$

Equation 3 may be expressed explicitly in terms of the temperature rate:

$$
\dot{\mathrm{T}}=\mathrm{M}_{\mathrm{GLOBAL}}^{-1}\left(\mathrm{Q}-\mathrm{K}_{\mathrm{GLOBAL}} \mathrm{T}\right)
$$

With axial symmetry, the projectile's geometry is defined in the (r-z) half-plane. This study considers triangular, three-node elements, having a linear temperature distribution within the element. The temperature, $\mathrm{T}_{\mathrm{r}, \mathrm{z}}$, at any point within an element is given as a function of the node temperatures, $T_{i}$ and the shape interpolation function given by the $\mathrm{N}_{\mathrm{i}}$ vector:

$\mathrm{T}_{\mathrm{r}, \mathrm{z}}=\left[\begin{array}{lll}\mathrm{N}_{1} & \mathrm{~N}_{2} & \mathrm{~N}_{3}\end{array}\right]\left[\begin{array}{c}\mathrm{T}_{1} \\ \mathrm{~T}_{2} \\ \mathrm{~T}_{3}\end{array}\right]$

The radius of the centroid for an element is given as:

$\overline{\mathrm{r}}=\frac{\mathrm{r}_{1}+\mathrm{r}_{2}+\mathrm{r}_{3}}{3} \mathrm{z}$

The centroid radius approximation states that, for elements sufficiently far away from a body's centerline, the radius of any point within the element is approximately equal to the radius of the element's centroid. This assumption is valid when:

$\frac{\overline{\mathrm{r}}}{\mathrm{r}_{\mathrm{EL}, \mathrm{MAX}}-\mathrm{r}_{\mathrm{EL}, \mathrm{MIN}}}>>1$

In this study, the centroid radius approximation will be applied throughout the geometry, with the understanding that some accuracy is lost near the centerline of the model. This approach has been used previously by Louaayou et al. (2008). The centroid radius approximations simplifies Eq. 2 by treating $\mathrm{r}$ as a constant within the element and allowing its elimination.

The element temperature gradient matrix $\mathrm{B}\left(\mathrm{m}^{-1}\right)$ is given as:

$$
B=\frac{1}{\operatorname{det}(J)}\left[\begin{array}{ccc}
z_{2}-z_{3} & z_{3}-z_{1} & z_{1}-z_{2} \\
r_{3}-r_{2} & r_{1}-r_{3} & r_{2}-r_{1}
\end{array}\right]
$$

where, $\mathbf{J}$ is the element Jacobian matrix $(\mathrm{m})$, given as:

$J=\left[\begin{array}{ll}\left(r_{1}-r_{3}\right) & \left(z_{1}-z_{3}\right) \\ \left(r_{2}-r_{3}\right) & \left(z_{2}-z_{3}\right)\end{array}\right]$ 
The elemental thermal conductivity matrix, $\mathrm{K}_{\mathrm{EL}}$ $\left(\mathrm{W} \cdot \mathrm{K}^{-1}\right)$, may now be expressed as:

$$
\mathrm{K}_{\mathrm{EL}}=2 \pi \overline{\mathrm{r}} \mathrm{A}_{\mathrm{EL}} \mathrm{k} \cdot \mathrm{B}^{\mathrm{T}} \mathrm{B}
$$

Similarly, the element heat capacity matrix, $\mathrm{M}_{\mathrm{EL}}$ $\left(\mathrm{J} \cdot \mathrm{kg}^{-1} \cdot \mathrm{K}^{-1}\right)$, may be shown to be given by:

$$
\mathrm{M}_{\mathrm{EL}}=\frac{\pi \mathrm{A}_{\mathrm{EL}} \rho \mathrm{c}}{10}\left[\begin{array}{ccc}
\frac{4}{3} \mathrm{r}_{1}+2 \overline{\mathrm{r}} & 2 \overline{\mathrm{r}}-\frac{\mathrm{r}_{3}}{3} & 2 \overline{\mathrm{r}}-\frac{\mathrm{r}_{2}}{3} \\
2 \overline{\mathrm{r}}-\frac{\mathrm{r}_{3}}{3} & \frac{4}{3} \mathrm{r}_{2}+2 \overline{\mathrm{r}} & 2 \overline{\mathrm{r}}-\frac{\mathrm{r}_{1}}{3} \\
2 \overline{\mathrm{r}}-\frac{\mathrm{r}_{2}}{3} & 2 \overline{\mathrm{r}}-\frac{\mathrm{r}_{1}}{3} & \frac{4}{3} \mathrm{r}_{3}+2 \overline{\mathrm{r}}
\end{array}\right]
$$

The global thermal conductivity matrix is assembled by mapping the individual element matrices to the appropriate locations in the global matrix. The global heat capacity matrix is likewise assembled:

$$
\begin{aligned}
\mathrm{K}_{\mathrm{GLOBAL}} & =\sum \mathrm{K}_{\mathrm{EL}} \\
\mathrm{M}_{\mathrm{GLOBAL}} & =\sum \mathrm{M}_{\mathrm{EL}}
\end{aligned}
$$

The simulation recognizes that the thermophysical properties of matter are temperature dependent, so that Eq. 10-13 require recalculation at each integration step. Linear interpolation is used to calculate values between points on data tables.

The fourth-order Runge-Kutta method was used in the time integration of Eq. 4. A time step of $5 \mu$ s was used to provide adequate resolution, 145 steps, during internal ballistics. The transition from internal to external ballistics, when the projectile exits the barrel, is assumed to be instantaneous. During external ballistics, a $10 \mu$ s integration time is used. With this time step, the largest Fourier number in the mesh occurs in a $0.125 \mathrm{~mm}$ copper element having a temperature of $27^{\circ} \mathrm{C}(300 \mathrm{~K})$. The resulting Fourier number, 0.037, indicates numerical stability in the simulation.

The simulation models a $.40 \quad \mathrm{~S} \& \mathrm{~W}$-caliber projectile, consisting of a lead core covered with a uniform, $0.25 \mathrm{~mm}$ thick copper jacket. The projectile is $15.5 \mathrm{~mm}$ in length and $10 \mathrm{~mm}$ in diameter. Elements range in size from $0.125-0.5 \mathrm{~mm}$. Figure 1 shows the finite-element mesh used for this study. At the beginning of the simulation, the projectile is assumed to be at a uniform, $20^{\circ} \mathrm{C}$ temperature.

Boundary conditions: Four boundary conditions are modeled in the simulation. During internal ballistics, the simulation models frictional heating between the projectile and the gun barrel and convection with the combustion gasses at the base of the projectile.

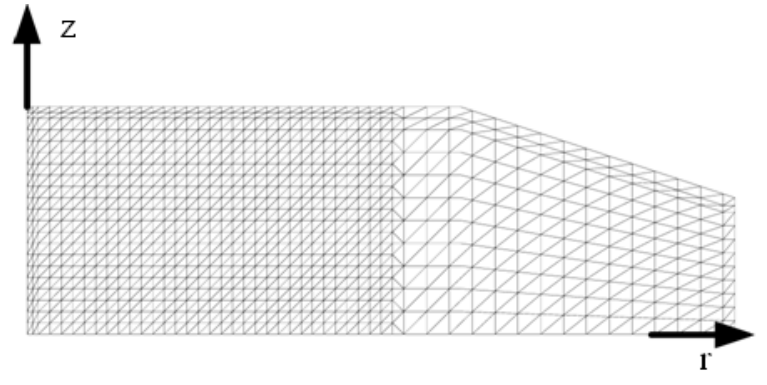

Fig. 1: Finite element mesh of projectile, in r-z halfplane

During external ballistics, forced convection and radiation at the surface of the projectile are considered. Convection at the nose of the projectile during internal ballistics is ignored, as it is assumed that the temperature difference between exposed surface of the projectile and the air in the gun barrel is negligible. Conduction heat transfer between the projectile and the gun barrel wall is explicitly modeled, but is considered with friction as both phenomena act over the same surface.

Friction boundary condition: Friction between the projectile and the gun barrel creates heat in both. The instantaneous heat flux at the interface, $\mathrm{q}_{\mathrm{FRIC}}^{\prime \prime}\left(\mathrm{W} \cdot \mathrm{m}^{-2}\right)$, is proportional to the frictional force and the velocity:

$\mathrm{q}_{\mathrm{FRIC}}^{\prime \prime}=\frac{\mathrm{F}_{\mathrm{FRIC}}}{\mathrm{A}_{\mathrm{BRG}}} \dot{\mathrm{x}}$

Where:

$\mathrm{F}_{\mathrm{FRIC}}=$ The frictional force $(\mathrm{N})$

$\mathrm{A}_{\mathrm{BRG}}=$ The bearing area of the projectile against the gun barrel wall $\left(\mathrm{m}^{2}\right)$

$\dot{\mathrm{x}}=$ The instantaneous velocity of the projectile $\left(\mathrm{m} \cdot \mathrm{sec}^{-1}\right)$

Based on Woodley et al. (2007) and other previous works describing the linear motion of a projectile during internal ballistics, the acceleration is assumed to be parabolic:

$\ddot{\mathrm{x}}=\mathrm{k}_{\mathrm{IB}} \mathrm{t}\left(\tau_{\mathrm{IB}}-\mathrm{t}\right)$

Where:

$\ddot{\mathrm{x}}=$ The linear acceleration of the projectile $\left(\mathrm{m} \cdot \mathrm{sec}^{-2}\right)$

$\mathrm{t} \quad=$ Elapsed time $(\mathrm{s})$

$\tau_{\mathrm{IB}}=$ The total duration of the internal ballistics (s)

$\mathrm{k}_{\mathrm{IB}}=\mathrm{A}$ constant $\left(\mathrm{m} \cdot \mathrm{sec}^{-4}\right)$ 
Integration of Eq. 15 with the appropriate initial conditions yields velocity and position as a function of time.

$$
\dot{\mathrm{x}}=\frac{\mathrm{k}_{\mathrm{IB}} \tau_{\mathrm{IB}} \mathrm{t}^{2}}{2}-\frac{\mathrm{k}_{\mathrm{IB}} \mathrm{t}^{3}}{3}
$$

$\mathrm{x}=\frac{\mathrm{k}_{\mathrm{IB}} \mathrm{t}^{3}}{6}-\frac{\mathrm{k}_{\mathrm{IB}} \mathrm{t}^{4}}{12}$

Constants $\mathrm{k}_{\mathrm{IB}}$ and $\tau_{\mathrm{IB}}$ may be determined by applying the known boundary conditions. At time $\mathrm{t}=\tau_{\mathrm{IB}}$, the projectile leaves the muzzle with a known muzzle velocity, or:

$$
\begin{aligned}
& \mathrm{x}\left(\tau_{\mathrm{IB}}\right)=1_{\text {BARREL }} \\
& \dot{\mathrm{x}}\left(\tau_{\mathrm{IB}}\right)=\dot{\mathrm{x}}_{\text {MUZZLE }}
\end{aligned}
$$

Substitution of Eq. 18 and 19 into Eq. 16 and 17 yields:

$$
\begin{aligned}
& \tau_{\mathrm{IB}}=\frac{2 \mathrm{l}_{\text {BARREL }}}{\dot{\mathrm{x}}_{\text {MUZZLE }}} \\
& \mathrm{k}_{\mathrm{IB}}=\frac{12 \cdot 1_{\text {BARREL }}}{\tau_{\mathrm{IB}}^{4}}=\frac{3 \dot{\mathrm{x}}_{\text {MUZZLE }}^{4}}{41_{\text {BARREL }}^{3}}
\end{aligned}
$$

Using values of $100 \mathrm{~mm}$ and $276 \mathrm{~m} \cdot \mathrm{sec}^{-1}$ for $1_{\text {BARREL }}$ and $\dot{\mathrm{x}}_{\text {MUZZLE }}$ yields values of $725 \mu$ s for $\tau_{\text {IB }}$ and $4.35 \times 10^{12} \mathrm{~m} \cdot \mathrm{sec}^{-4}$ for $\mathrm{k}_{\mathrm{IB}}$.

The Newtonian equations of motion may be used to determine the magnitude of the frictional force, $\mathrm{F}_{\mathrm{FRIC}}$ $(\mathrm{N})$. Assuming the peak pressure $\left(\mathrm{P}_{\mathrm{MAX}}, \mathrm{Pa}\right)$ of the combustion gasses behind the projectile coincides with maximum acceleration:

$\mathrm{F}_{\mathrm{FRIC}}=\mathrm{P}_{\mathrm{MAX}} \mathrm{A}_{\mathrm{X}}-\ddot{\mathrm{x}}_{\mathrm{MAX}}$

For a $0.40 \mathrm{~S}$ and $\mathrm{W}$-caliber bullet, the peak pressure in the breech is on the order of $244 \mathrm{MPa}$ (35 ksi) and the mass, $\mathrm{m}$, of a typical projectile is 11.63 g. With these values, the friction force of Eq. 22 is $12,500 \mathrm{~N}$.

The exact value of friction and the heat it generates, is uncertain. The $12,500 \mathrm{~N}$ friction force is based on a maximum value for pressure; the actual pressure may differ due to variations in the propellant charge and leakage of gasses from the breach and around the projectile. The heat generated by friction is absorbed not only by the projectile, but also by the gun barrel. In addition, thermal conduction occurs between these two components. Both friction and conduction depend on a number factors, including: heat retained in the gun barrel from previously-fired rounds; thermal expansion of the gun barrel which reduces the interference and thus the friction; accumulation of residue from previous rounds and; wear of the gun barrel. Practically, these factors are difficult, if not impossible, to predict and model in simulation.

The exact nature of the friction, though, is not as important as its magnitude. As will be discussed in the Results section, the duration of internal ballistics is too short to allow frictional heat to diffuse deep into the projectile. Instead, elevated temperatures from friction are only found near the surface when the projectile leaves the gun barrel. Therefore, the rate of heat transfer is not as important as the total heat developed by friction during internal ballistics. To model the frictional heat absorbed by the gun barrel and capture the effects of conduction with the gun barrel, the authors apply a correction factor, e, to the heat flux of Eq. 14 in the simulation. The value of e, 0.025, was empirically selected to force surface temperatures to be similar to those cited by Richards (2002).

Internal convection boundary condition: Forced convection with combustion gasses at the base of the projectile is also considered during internal ballistics. The temperature of the gas is assumed to be $1727^{\circ} \mathrm{C}$ (3400 K) based on work by Ray and Tezduyar (2000) the convection coefficient at the base is assumed to be $5000 \mathrm{~W} \cdot \mathrm{m}^{-2} \cdot \mathrm{K}^{-1}$, an estimate based on representative values listed by Edward Pope (1997). The value used in the simulation is inflated by two orders of magnitude, as the high pressure in the breech chamber is expected to result in a higher heat transfer at the base. The net contribution of internal convection to the temperatures in the projectile, though, is expected to be minimal. Considering a semi-infinite lead solid starting at a uniform temperature and having its surface exposed to convection, the closed-form solution for temperature as a function of depth, $x$ and time, $t$, is given by:

$$
\begin{aligned}
\frac{\mathrm{T}(\mathrm{x}, \mathrm{t})-\mathrm{T}_{\mathrm{i}}}{\mathrm{T}_{\infty}-\mathrm{T}_{\mathrm{i}}}=\operatorname{erfc}( & \left.\frac{\mathrm{x}}{2 \sqrt{\alpha \mathrm{t}}}\right)-\left(\exp \left(\frac{\mathrm{hx}}{\mathrm{k}}+\frac{\mathrm{h}^{2} \alpha \mathrm{t}}{\mathrm{k}^{2}}\right)\right) \\
& \left(\operatorname{erfc}\left(\frac{\mathrm{x}}{2 \sqrt{\alpha \mathrm{t}}}+\frac{\mathrm{h} \sqrt{\alpha \mathrm{t}}}{\mathrm{k}}\right)\right)
\end{aligned}
$$

Using the stated convection parameters over an interval of $725 \mu \mathrm{s}$, equal to that of internal ballistics, the 
surface temperature of the solid will be $84.6^{\circ} \mathrm{C}$. At a depth of $0.2 \mathrm{~mm}$, the temperature is only $31.9^{\circ} \mathrm{C}$. The shallow depth of heating and the relatively low surface temperature indicate minimal heat transfer to the projectile from forced convection with the propellant gasses. This finding supports earlier claims by Carlucci et al. (2006).

External convection boundary condition: Considering a project, $15.5 \mathrm{~mm}$ long, having a surface temperature of $277^{\circ} \mathrm{C}$ and traveling in a standard atmosphere at $276 \mathrm{~m} \cdot \mathrm{sec}^{-1}$ (Mach 0.8). Under these conditions, the Reynold's number is 94,000 , indicating laminar flow as $\operatorname{Re}<\operatorname{Re}_{\text {CRIT }}=200,000$. In laminar flow conditions, the average forced-convection coefficient, $\mathrm{h}_{\mathrm{AVG}}\left(\mathrm{W} \cdot \mathrm{m}^{-2} \cdot \mathrm{K}^{-1}\right)$, may be calculated using classical methods:

$\mathrm{h}_{\mathrm{AVG}}=\mathrm{Nu}(\mathrm{l}) \frac{\mathrm{k}}{1}=0.664 \frac{\mathrm{k}}{1} \operatorname{Re}^{1 / 2} \operatorname{Pr}^{1 / 3}$

For the $15.5-\mathrm{mm}$ projectile, the convection coefficient is $507 \mathrm{~W} \cdot \mathrm{m}^{-2} \cdot \mathrm{K}^{-1}$.

The simulation applies Eq. 24 to the nose and lateral surfaces of the projectile during external ballistics. Flow separation is assumed to occur at the base, so it is exposed to a turbulent wake. The convection coefficient of the wake is assumed to be half that of the lateral surface. As will be seen in the Results section, temperatures in the projectile are relatively insensitive to the external convection, so that errors arising from this approximation are not significant.

The projectile is assumed to have a constant velocity through its trajectory.

Radiation boundary condition: Radiative heat transfer to the environment is considered during external ballistics. The projectile's surface is assumed to be nearly-fully oxidized copper with an emissivity of 0.4 and the environment is assumed to have a uniform temperature of $20^{\circ} \mathrm{C}(293 \mathrm{~K})$.

Model validation: To determine the accuracy of the finite-element simulation, it is applied to situations for which analytical solutions exist, both steady-state and transient. The simulation also models projectiles having temperature-sensitive paraffin payloads. Comparison simulation predictions with test articles will further validate the simulation.

The steady-state verification considers a solid lead cylinder, $10 \mathrm{~mm}$ in diameter and $16 \mathrm{~mm}$ in length. One face of the cylinder is exposed to a $327^{\circ} \mathrm{C}(600 \mathrm{~K})$ fluid with a convection coefficient of $1000 \mathrm{~W} \cdot \mathrm{m}^{-2} \cdot \mathrm{K}^{-1}$. The other face is exposed to a $27^{\circ} \mathrm{C}(300 \mathrm{~K})$ fluid with a $100 \mathrm{~W} \cdot \mathrm{m}^{-2} \cdot \mathrm{K}^{-1}$ coefficient. The lateral surface of the cylinder is perfectly insulated. Assuming temperatureinvariant material properties (at $571 \mathrm{~K}$ ) in the cylinder, the surface temperatures, $T_{1}$ and $T_{2}(K)$, may be found analytically to be 573.92 and $560.69 \mathrm{~K}$, respectively. The simulation models the cylinder with $1 \times 1 \mathrm{~mm}$ triangular elements and is allowed to run to steady-state from a uniform starting temperature. It returns surface temperatures of 573.96 and $560.79 \mathrm{~K}$, in excellent agreement with the analytical solution.

Verification of the simulation's transient performance considers again a solid lead cylinder, 10 $\mathrm{mm}$ in diameter and $16 \mathrm{~mm}$ in length, starting at a uniform temperature and being immersed in a heated fluid so that all external surfaces have a convection coefficient $500 \mathrm{~W} \cdot \mathrm{m}^{-2} \cdot \mathrm{K}^{-1}$. The Biot number under these circumstances, 0.027 , indicates that the diffusion of heat inside the cylinder is "faster" than the convection, so that temperatures in the cylinder will be nearly uniform. The time constant for the cylinder's temperature with respect to that of the fluid, $\tau$, is $5.57 \mathrm{sec}$; the temperature as a function of time is given as:

$\frac{\mathrm{T}-\mathrm{T}_{\infty}}{\mathrm{T}_{\mathrm{INIT}}-\mathrm{T}_{\infty}}=1-\exp \left(\frac{-\mathrm{t}}{\tau}\right)$

At any point in time, the simulated temperatures in the cylinder are nearly uniform and the timetemperature curve is almost indistinguishable from that predicted by Eq. 25 .

Further validation is obtained through comparison of simulation predictions to test articles recovered after firing. A paraffin insert, $4.8 \mathrm{~mm}$ in length and $3.2 \mathrm{~mm}$ in diameter, is press-fit into a hole drilled into the base of the bullet. Paraffin is selected due to its low melting point $\left(55^{\circ} \mathrm{C}\right)$, as melting would indicate this temperature being reached. After assembling the bullet into a cartridge, it is fired and recovered in a water trap. Water serves to slow the projectile without damage and rapidly cool from the projectile.

Simulation of the paraffin-bearing projectile predicts a thin layer of heated paraffin at the surface exposed to the combustion gasses, with temperatures between 119 and $159^{\circ} \mathrm{C}$. Because the simulation does not consider possible phase changes nor the heat of fusion of materials, these temperatures cannot be considered accurate. It may be inferred, though, that the surface of the paraffin will experience some melting, but the bulk of the paraffin will remain solid. The 
recovered paraffin inserts do exhibit effects consistent with superficial surface melting-fine details have been "blurred" by melting and fluid flow and residue from combustion of the propellant is observed under the surface of the paraffin. Using an optical microscope, the depth of melting is measured to be less than $0.05 \mathrm{~mm}$.

\section{RESULTS}

The MATLAB simulation predicts the dynamic temperature distribution in a small-caliber projectile. Temperatures in the projectile as it leaves the gun barrel are shown in Fig. 2. Elevated temperatures, from 254$270^{\circ} \mathrm{C}$, are found only near the bearing surface, which was in frictional contact with the gun barrel. While this shows excellent agreement with Richard's measurement (Richards, 2002), it should be remembered that this result was forced using a correction factor on the friction. The distribution is consistent with Richard's data in that the high-speed infrared camera used by Richards only measured the surface temperature of the bullet. In addition, the temperature rise from convection with the combustion gasses at the base is negligible in comparison to that from friction.

Diffusion of the frictional heat through the projectile occurs during external ballistics. Figure 3 shows temperatures in the projectile at a distance of $40 \mathrm{~m}$ downrange. Assuming a constant velocity of $276 \mathrm{~m} \cdot \mathrm{sec}^{-1}$, this corresponds to a flight time of $145 \mathrm{~m} \mathrm{sec}$. Here, elevated temperatures have diffused through the projectile, but the peak temperature is only $56^{\circ} \mathrm{C}$.

The numerical values assigned to boundary conditions and material properties in the simulation have varying levels of uncertainty. As discussed earlier, friction at the projectile-gun barrel interface depends on several unknown and/or uncontrollable factors. Values for combustion gas convection are estimates based on previously published data. The thermal conductivity of

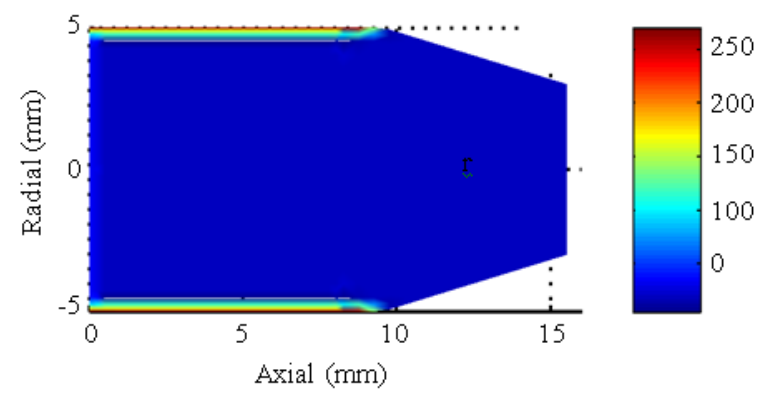

Fig. 2: Predicted temperatures in projectile at muzzle exit bullet materials depend on the alloys used in its construction. To ascertain the effect of these uncertain parameters, the simulation is repeated with changes to these parameters. Friction is changed by $\pm 25 \%$; internal convection, $\pm 50 \%$; external convection, $\pm 25 \%$ and thermal conductivity of projectile materials, $\pm 25 \%$.

Figure 4 shows the change in maximum temperature obtained by increasing the friction by $25 \%$. Near the bearing surface, the change in friction yields a $60^{\circ} \mathrm{C}$ increase in temperature. Through the bulk of the projectile, though, the increase in maximum temperature is less than $10^{\circ} \mathrm{C}$. Reducing the friction by $25 \%$ produces changes in temperature that are approximately symmetric to Fig. 4. Other than friction, none of the parameters yield a temperature difference of more than $10^{\circ} \mathrm{C}$. Table 1 shows the changes in predicted temperatures from the uncertainty analysis.

The simulation is applied to predict temperatures in a bullet with a MEMS device mounted on its base. The device is assumed to be a silicon wafer, $250 \mu \mathrm{m}$ thick, with negligibly-small surface-micromachined features. The device has a PMMA (poly methyl methacrylate) package, $250 \mu \mathrm{m}$-thick, in intimate contact with the silicon device on both sides. These assumptions are conservative as they ignore any cavities that would slow heat transfer to the device. Elements $0.125 \mathrm{~mm}$ thick are used to model the device and the package. Internal heating of the MEMS device is ignored.

Table 1: Differences in temperature resulting from uncertainty in simulation parameters

\begin{tabular}{|c|c|c|}
\hline Parameter & Change & Results \\
\hline Projectile-barr & $\pm 25 \%$ & lum temperature \\
\hline th & $\pm 50 \%$ & $\begin{array}{l} \pm 8^{\circ} \mathrm{C} \text { in maximum temperature at } \\
\text { base }\end{array}$ \\
\hline Extern & $\pm 25^{\circ}$ & $\begin{array}{l} \pm 0.6^{\circ} \mathrm{C} \text { in surface temperature, } \\
40 \mathrm{~m} \text { downrange }\end{array}$ \\
\hline $\begin{array}{l}\text { Thermal conductivity in } \\
\text { bullet materials }\end{array}$ & $\pm 25 \%$ & $\begin{array}{l}-6^{\circ} \mathrm{C} /+4^{\circ} \mathrm{C} \text { in maximum } \\
\text { temperature at core }\end{array}$ \\
\hline
\end{tabular}

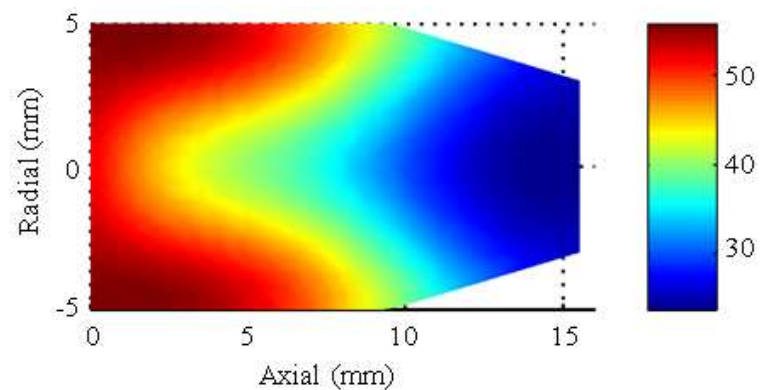

Fig. 3: Predicted temperatures in projectile, $40 \mathrm{~m}$ downrange 


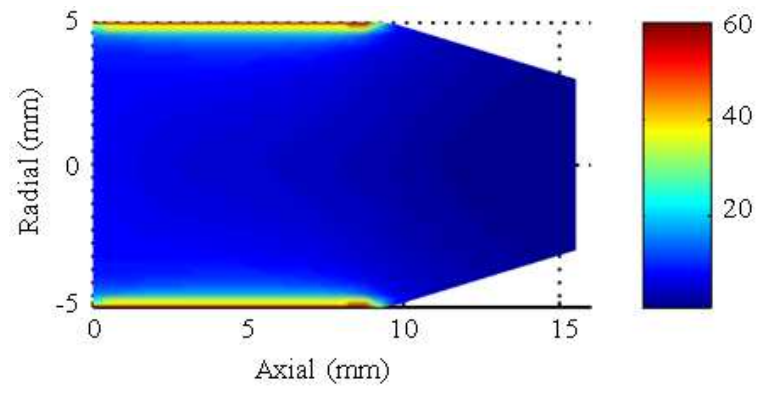

Fig. 4: Changes in maximum temperature obtained by increasing friction $25 \%$



Fig. 5: Predicted temperatures in projectile with MEMS on base, $80 \mathrm{~m}$ downrange

Figure 5 shows the predicted temperatures in the MEMS bullet, $80 \mathrm{~m}$ downrange. A longer range is used as temperatures in the silicon are still increasing, albeit asymptotically; $80 \mathrm{~m}$ is selected as a practical limit to the effective range of a handgun. At this range, temperatures in the silicon wafer vary between $26.2^{\circ} \mathrm{C}$ and $29.1^{\circ} \mathrm{C}$. These temperatures are compatible with common materials used in the manufacture of MEMS.

This simulation result is confirmed experimentally. A surface-mount LED (Lumex Inc., P/N SMLLXL1209SUGC-TR) is inserted into the base of a bullet to act as a proxy for a MEMS device. The LED is secured with paraffin and its dome is fully exposed to the combustion gasses during internal ballistics. Two bullets were assembled, fired and recovered. The LED's survived intact with minor surface damage, thought to be the result of direct contact with burning propellant grains. Both were mechanically extracted from the paraffin and found to function normally. The survival of the LED's support the simulation finding that a polymer package can protect a MEMS device from extremes in temperature.

\section{DISCUSSION}

Simulation results show that elevated temperatures in a small-caliber projectile are primarily the result of friction at the gun barrel interface. Due to the low diffusivity of lead and the short duration of the internal ballistics, temperatures in excess of $100^{\circ} \mathrm{C}$ are found only near the bearing surface of the projectile as it leaves the gun barrel. Through external ballistics, the frictional heat will diffuse through the projectile. At a distance of $40 \mathrm{~m}$ downrange, the peak temperature in the projectile is $56^{\circ} \mathrm{C}$, which is less than the $71^{\circ} \mathrm{C}$ used in acceptance testing of munitions by the US Army (Carlucci et al., 2006). The implication is that a MEMS device, placed anywhere except the bearing surface of the projectile, will not suffer damage from temperatures associated with firing the projectile.

\section{CONCLUSION}

Further, a PMMA package will provide additional thermal protection for a MEMS sensor in a projectile, keeping temperatures below $30^{\circ} \mathrm{C}$ in the silicon. This protection is attributed to the high specific heat and low thermal conductivity of the PMMA package, which attenuate the heat flow to the silicon wafer. The broader conclusion to be drawn is that a polymer package can provide adequate protection against the high temperatures encountered during the ballistic cycle.

\section{REFERENCES}

Ahmed, N., R.D. Brown and A. Hameed, 2008. Finite element modeling and simulation of gun dynamics using 'ANSYS'. Proceeding of the 10th International Conference on Computer Modeling and Simulation, Apr. 1-3, IEEE Xplore Press, Cambridge, New York, UK., pp: 18-22. DOI: 10.1109/UKSIM.2008.22

Carlucci, D.E., J. Cordes, J. Hahn and A. Frydman, 2006. Electronics and the gun environment. Ferroelectrics, 342: 193-204. DOI: $10.1080 / 00150190600946377$

Edward Pope, J., 1997. Rules of Thumb for Mechanical Engineers. Gulf Publishing Company, Houston, TX., ISBN: 0-88415-790-3, pp: 26.

Goodin, D. and N. Alexander, 2002. Emplacing sensors in urban terrain. General Atomics, San Diego, CA. http://web.gat.com/pubsext/MISCONF03/A24253.pdf

Kleiner, K., 2009. Radio-Controlled Bullets Leave No Place to Hide. New Scientist, 2711: 22. http://www.newscientist.com/article/mg20227116. 900-radiocontrolled-bullets-leave-no-place-tohide.html

Louaayou, M., N. Nait-Said and F.Z. Louai, 2008. 2D finite element method study of the stimulation induction heating in synchronic thermography NDT. NDT E Int., 41: 577-581. DOI: 0.1016/j.ndteint.2008.07.001 
Ray, S.E. and T.E. Tezduyar, 2000. Fluid-object interactions in interior ballistics. Comput. Methods Applied Mech. Eng., 190: 363-372. DOI: 10.1016/S0045-7825(00)00207-3

Richards, A., 2002. How to Measure the Temperature of a Speeding Bullet. $\mathrm{R}$ and $\mathrm{D}$ Magazine. http://www.corebyindigo.com/PDF/articles/R\&D_ article.pdf

Schubert, F.N. and T.L. Kraus, 1995. The whirlwind war: United States army in operations desert shield and desert storm. US Army Center of Military History, Washington, DC. http://www.history.army.mil/books/www/Wwindx. htm

Stiefel, L., 1988. Pressure-Time-Velocity-Travel Relationship in Typical Gun Systems. In: Progress in Astronautics and Aeronautics, Summerfield, M. (Ed.). American Institute of Aeronautics and Astronautics, Washington DC., USA., ISBN: 0930403207, pp: 61-74.

Tobik, T., 2006. Air Force fuze technology. AFRL Munitions Directorate. http://www.dtic.mil/ndia/2006fuze/tobik.pdf
Tuscon, A.Z., 2006. Paveway laser and GPS/laser precision guided bombs. Raytheon Company Missile Systems.

http://www.raytheon.com/capabilities/rtnwcm/grou ps/rms/documents/content/rtn_rms_ps_pavewayfm _datasheet.pdf

Tuscon, A.Z., 2008. Excalibur-precision-guided, long range, $155 \mathrm{~mm}$ artillery projectile. Raytheon Missile Systems.

http://www.raytheon.com/capabilities/rtnwcm/grou ps/rms/documents/content/rtn_rms_ps_excalibur_d atasheet.pdf

Woodley, C., A. Carriere, P. Franco, J. Nussbaum, X. Chabaux and B. Longuet, 2007. Comparisons of internal ballistics simulations of $40 \mathrm{~mm}$ gun firings. Proceeding of the 23rd International Symposium Ballistics, Apr. 16-20, International Ballistics Society, Tarragona, Spain, pp: 359-367. http://www.mater.upm.es/isb2007/Proceedings/PD F/Volume_1/Vol.I(42)IB03.pdf 